\title{
Laboreal
}

Volume $3 \mathrm{~N}^{\circ} 2$ | 2007

Trabalho infantil

\section{Los países ricos y los ninõs que trabajan : la paradoja occidental}

Países ricos e trabalho de menores : o paradoxo ocidental

Pays riches et enfants qui travaillent: un paradoxe occidental

Rich countries and child labour : the occidental paradox

\section{Gianni Paone}

Traductor. Andrea Pistone

\section{OpenEdition}

\section{Journals}

\section{Edición electrónica}

URL: http://journals.openedition.org/laboreal/12392

DOI: 10.4000/laboreal.12392

ISSN: 1646-5237

Editor

Universidade do Porto

\section{Referencia electrónica}

Gianni Paone, «Los países ricos y los ninõs que trabajan : la paradoja occidental », Laboreal [En línea], Volume 3 No2 | 2007, Publicado el 01 diciembre 2007, consultado el 10 diciembre 2020. URL : http:// journals.openedition.org/laboreal/12392 ; DOI : https://doi.org/10.4000/laboreal.12392

Este documento fue generado automáticamente el 10 diciembre 2020.

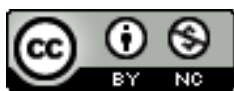

Laboreal está licenciado com uma Licença Creative Commons - Atribuição-NãoComercial 4.0 Internacional. 


\title{
Los países ricos y los ninõs que trabajan : la paradoja occidental
}

\author{
Países ricos e trabalho de menores: o paradoxo ocidental \\ Pays riches et enfants qui travaillent: un paradoxe occidental \\ Rich countries and child labour : the occidental paradox
}

\section{Gianni Paone}

Tradución : Andrea Pistone

\section{NOTA DEL EDITOR}

Manuscrito recebido em : Abril/2007

Aceite após peritagem em : Setembro/2007

\section{Introducción}

1 El trabajo de menores es un fenómeno difundido : en Asia (127 millones, aprox. el $60 \%$ ) y en África (61 millones, aprox. el $29 \%$ ) se encuentran los porcentajes mayores de trabajo de menores (ILO, 2002). Además, también en los países industrializados está presente la mano de obra de menores con modalidades y características diferentes de los demás países en el mundo.

2 Estudiar el fenómeno del trabajo de menores, especialmente si nos referimos a las sociedades occidentales e industrializadas - Europa y Estados Unidos significa enfrentarse a una temática muy compleja que consta de distintos niveles de análisis.

3 Las categorías empleadas a menudo en el estudio del trabajo de menores en aquellos que se definen "países en desarrollo" (ej. Brasil, NT), acaban siendo insuficientes y hasta equivocadas, si tomadas como referencia para los países industriales. De hecho, las fronteras entre ingreso laboral precoz y explotación, entre frecuencia escolar y trabajo, entre socialización y exclusión a través del trabajo de menores, parecen menos 
definidas, si comparadas con las relaciones que se establecen entre similares categorías en los países de África y Asia donde el trabajo de menores, también en sus peores formas, es una realidad bien visible, que ha sido objeto de estudios más o menos recientes y en la cual existen muchos datos también desde el punto de vista de la investigación estadística y social. Con referencia a la Unión Europea, decir que el problema del trabajo de menores no ha sido adecuadamente estudiado y documentado, y como en otras realidades geográficas, acaba siendo necesario examinar los aspectos y contextos culturales, sociales y económicos que caracterizan y distinguen no solo un país del otro, sino también un área de la otra dentro del mismo país.

4 Para estimar el fenómeno es necesario poder comparar los distintos datos estadísticos nacionales. La diferencia de estadísticos, así como los tipos empleados y la naturaleza compleja del fenómeno para investigar, dificultan el trabajo de estimación. Muchos países no registran las actividades de menores que por ley no deberían trabajar, así como es difícil el censo de aquellos ámbitos de trabajo como el servicio doméstico, el trabajo en agricultura y en particular en el sector informal que, a razón de su naturaleza "sumergida", son los ambientes mas favorables por la demanda-oferta de mano de obra de menores. (Paone \& Teselli, 2000).

Investigar, conocer y combatir el fenómeno del trabajo de menores, en sus formas más peligrosas para la salud y el bienestar de los menores, significa intervenir con medidas de prevención, con programas y acciones positivas para evitar, o por lo menos limitar, el impacto negativo que una actividad de trabajo en edad precoz puede tener sobre el desarrollo físico e intelectual de chicos y chicas, y aún más en niños y niñas.

\section{El trabajo de menores en el Oeste}

6 Antes que todo, hay que distinguir entre trabajo de menores ilegal y trabajo de menores no regular. La ilegalidad se da cuando no viene respetado el límite mínimo de edad por el comienzo del trabajo. En la mayoría de los países este limite varia entre 14 y 15 años de edad, paralelamente a la obligatoriedad de la instrucción escolar. Más allá de los 15 anos de edad, y siempre para allá del límite fijado por la legislación del Estado de referencia, el trabajo de menores se admite en las formas establecidas por las leyes actuales. En este periodo de edad se pueden destacar fenómenos de irregularidad del trabajo (p.e. aquellos relativos a la seguridad y al trabajo nocturno).

Muchos piensan que el trabajo de menores ha finalmente desaparecido en las sociedades occidentales. No es así, y en este estudio se presentarán en comparación los datos disponibles por las fuentes oficiales, las agencias estadísticas internacionales reconocidas y las investigaciones de institutos. El objetivo final es comprender si en las sociedades económicamente adelantadas el fenómeno del trabajo de menores ha definitivamente desaparecido o si está todavía presente, $\mathrm{y}$, en este caso, como se caracteriza.

El escenario de referencia es el constituido por los países del Unión Europea. Comprender y conocer analogías y diferencias entre distintas áreas geográficas, primariamente con referencia a las condiciones de infancia y adolescencia, significa establecer las bases para activar, en un futuro próximo, acciones, políticas y estrategias contra las desigualdades sociales. Conocer las causas y las formas en las cuales se manifiesta un fenómeno como el del trabajo de menores significa estar en grado de 
realizar intervenciones adecuadas para la superación de las disparidades socioculturales y económicas que constituyen su origen.

\section{El contexto histórico - analítico}

Aunque el trabajo de menores como problema social haya surgido como consecuencia de la revolución industrial, los niños siempre han trabajado, en las tareas de casa, en los trabajos agrícolas, desde muy jóvenes han sido empleados en tareas que generalmente habían sido aceptadas por el contexto sociocultural y económico de referencia.

Este panorama empieza a cambiar, en el siglo XVIII, con la inserción laboral de niños durante la revolución industrial en Gran Bretaña. La situación de niños en las minas ingleses y en las industrias textiles ha sido objeto de muchos debates parlamentares a lo largo del siglo XIX (por ej. Con referencia a la situación de los jóvenes deshollinadores y las consecuentes enfermedades pulmonares). También con las leyes se empezó a introducir, gradualmente, la condena para muchas de estas actividades. En aquellos años se introduce el trabajo part-time con el Factory Acts en el 1833 y 1844. Con el Education Act del 1918 empieza el proceso de abolición del trabajo de menores, que se extiende con el Young Person's Act del 1933 con el cual se ponen limites de edad y de formas de trabajo peligrosas. Se destaca el debate acerca de las reales consecuencias y sobre los efectos producidos por las leyes establecidas.

11 Por un lado, de hecho, muchos menores seguían a ser empleados en actividades laborales prohibidas por la Ley, y las inspecciones y controles fracasaron; por otro lado, mientras que el trabajo en Reino Unido desminuía en el paso del siglo XIX al siglo $\mathrm{XX}$, muchos estudios tendían a minimizar el rol de la Ley misma, destacando cuales factores principales en contra del trabajo de menores, la oferta educacional y la importancia de la Instrucción valorada por las familias inglesas; otros aún, veían en el aumento de la renta familiar una parada para la difusión del trabajo de menores.

12 No es fácil buscar aclarar estos aspectos porque causas y efectos están simultáneamente e intensamente correlacionados. La experiencia en Inglaterra se encuentra también en otros países, mas bien en la fase de la primera industrialización, aunque cada uno con su historia distinta. Los primeros años de industrialización han sido caracterizados por un importante rol de los menores en la fuerza de trabajo, aunque en algunos países, como p.e. Japón, esta presencia era atenuada por el valor cultural atribuido a la libertad para que los niños jueguen. Además el aumento de la atención pública con referencia a la salud y a la seguridad de los menores ha contribuido a una mayor sensibilización también a través de las leyes. Paralelamente la instrucción de masa (pública) y el incremento de la renta general han jugado un rol importante en cambiar el actitud, institucional y no hacía el empleo de mano de obra de menores.

Esto ha implicado que muchos países europeos hayan coincidido en un nuevo modelo de empleo de menores. A lo largo de estas últimas décadas, a partir de los años 60 del siglo pasado, el incremento de la tasa escolar ha implicado una disminución evidente del trabajo de menores en Europa. Esto llevó a la conclusión, a menudo equivocada, que estando el trabajo de menores estrechamente relacionado con el abandono escolar, en el momento en que la tasa de frecuencia escolar aumentaba, lo lógico era que hubiera habido una consecuente disminución de trabajo de menores. Esta hipótesis, que podía ser exacta en los países no industrializados, sigue siendo insuficiente y parcial si considerada para los países industrializados como Europa y Estados Unidos. En este 
caso de hecho el trabajo de menores se manifiesta con formas y modalidades del todo nuevas respeto a los modelos existentes en África o Asia. Una consecuencia ulterior ha sido ver desminuir la atención de los investigadores y de los institutos públicos sobre el fenómeno del trabajo de menores, lo que ha causado la casi absoluta falta de datos y estudios sobre el mismo. Solo hace poco, como consecuencia de las denuncias hechas por asociaciones o sindicados, algunos Países Europeos han empezado a estudiar y hacer un censo oficial del trabajo de menores, confirmando, también con datos, la existencia y la extensión del fenómeno, con características similares al pasado y en parte típicas de nuestra sociedad moderna y post-moderna.

\section{Los últimos datos de trabajo de menores}

En el 2002, el ILO (Internacional Labour Office) ha actualizado sus últimas estimaciones (valoración estadística, NT) mundiales proponiendo la hipótesis de una difusión del trabajo de menores en el mundo con un número de implicados con más de 211 millones de menores de 5 hasta 14 años, como muestran las siguientes tablas.

Datos globales de la población de menores que trabaja en el mundo

Datos globales de la población de menores que trabaja en el mundo

\begin{tabular}{c|c|c|c} 
Edad & $\begin{array}{c}\text { Total población } \\
(\mathbf{x} \text { 1000) }\end{array}$ & $\begin{array}{c}\text { trabajadores } \\
(\mathbf{x ~ 1 0 0 0 )}\end{array}$ & $\begin{array}{c}\% \\
\text { trabajadores }\end{array}$ \\
\hline $5-9$ & 600.200 & 73.100 & 12,2 \\
\hline $10-14$ & 599.200 & 137.700 & 23,0 \\
\hline Total & 1.199 .400 & 210.800 & 17,6 \\
\hline $15-17$ & 332.100 & 140.900 & 42,4 \\
\hline Total & 1.531 .100 & 351.700 & 23,0
\end{tabular}

Fuente: ILO/IPEC 2002 
Datos de trabajo de menores por áreas geográficas - 2000

Datos de trabajo de menores por áreas geográficas - 2000

\begin{tabular}{l|c|c}
\multicolumn{1}{c|}{ Área } & $\begin{array}{c}\text { Menores de 5-14 años } \\
\text { trabajadores } \\
\text { (millones) }\end{array}$ & \% trabajadores \\
\hline Países desarrollados & 2.5 & 2 \\
\hline $\begin{array}{l}\text { Países en desarrollo } \\
\text { (transición) }\end{array}$ & 2.4 & 4 \\
\hline Asia e Oceanía & 127.3 & 19 \\
\hline América latina y Caribe & 17.4 & 16 \\
\hline África sub-sahariana & 48.0 & 29 \\
\hline Medio oriente y & 13.4 & 15 \\
Norte de África & $\mathbf{2 1 1}$ & $\mathbf{1 8}$ \\
\hline Total & &
\end{tabular}

Fuente: ILO/IPEC 2002

\section{El trabajo de menores en los países desarrollados: consideraciones generales}

El trabajo de menores no existe solamente en los designados "países en desarrollo". Esto se da también con un porcentaje consistente y en ocupaciones muy variadas, también en los países en desarrollo.

En el sur de Europa un alto número de menores es empleado para actividades remuneradas, en particular actividades por temporadas (según estación, NT), trabajos de calle, pequeñas actividades comerciales o en trabajo en casa. Además, el trabajo de menores no ha desaparecido de los otros países europeos. Se ha dado su aumento en el Este de Europa, y en Europa Central, en particular después de la transición de la economía planificada por el comercio libre. En EEUU el número de menores entre los 12 y 17 años empleados en varias actividades laborales, es de 5,5 millones, casi el $27 \%$ del total de menores de edad. A estos se suman los menores de 12 años empleados en distintas actividades, p.e trabajos urbanos de venta de ropa, en el comercio ambulante, y en particular como trabajadores por temporada.

17 En Italia, una investigación del CGIL (Confederazione Generale Italiana del Lavoro) del 2000 (Paone \& Teselli) ha analizado el fenómeno estimando un número de casi 350 millones de casos, con referencia a distintos indicadores, como el abandono escolar, los accidentes en el trabajo, el porcentaje de menores trabajadores de comunidades extranjeras, la creciente difusión de formas mixtas de escuela-trabajo. Según la organización no-gubernamental Mani Tese, se calcula que en Gran Bretaña trabajen de varias formas por lo menos el $15 \%$ de chicos entre los 11 y 14 años de edad. En EEUU trabajan alrededor de 5 millones de chicos, y las violaciones de las normas que regulan el trabajo de menores han aumentado un $250 \%$ entre 1983 y 1990. Son datos 
que, aunque necesiten de ser revisados para sus garantías científicas, de toda forma hacen reflexionar.

El trabajo precoz se puede configurar como elección subjetiva en parte autónoma, fuente de gratificación profesional y generadora de independencia parcial. Desde este enfoque se explica el gradual empleo de menores en actividades de trabajos por temporadas y de precarios, cuya duración puede ser funcional para la adquisición de determinado bien de consumo.

El fenómeno está también presente en aquellos países que deberían ser de primera línea en la política de protección de menores, como p.e., Reino Unido, Italia y otros países europeos. En Reino Unido el desarrollo de trabajo de menores ha sido un efecto (consecuencia) de la política conservadora de los años 80 y de la "deregulation" que ha afectado las políticas de protección hacia los menores. Chicos, más bien de familias inmigradas, que trabajan en calles, restaurantes, empresas de limpieza, etc... Igualmente en Portugal, Italia, Grecia, España y EEUU. En Francia centenas de jóvenes no van a la escuela y un gran número de ellos son empleados en los trabajos más variados.

En algunas investigaciones se destaca como el trabajo de menores está relacionado con la ocupación de los mismos padres: la tasa de menores que trabaja aumenta pues considerablemente cuando los padres están empleados en actividades comerciales o artesanales.

Pero la influencia de la familia no se refiere solo al factor económico. La presencia del trabajo de menores puede ser también señal de una estrategia familiar dirigida a dar a los chicos una experiencia y una inserción profesional no garantizada hoy en día por la formación escolar y la posesión de un título de estudio.

El proceso educacional y formativo de las nuevas generaciones, confinado en esta edad, más que nada, en ámbito familiar y escolar, se viene pues integrando al trabajo, que pertenece propiamente al mundo de mayores. Frente a todo esto hay también una cierta desconfianza de los estudiantes hacía la escuela misma, presente sobretodo en los que vivencian una serie de fracasos escolares y una incapacidad de remediarlos, no solamente por parte de la propia escuela, pero también por parte de las familias, que parecen a veces considerar la institución escolar más como una parada, que como específico sistema formativo. La escuela llega pues a perder la función de institución capaz de mejorar el futuro de sus propios hijos. Pierde por lo tanto el atractivo y capacidad de implicación. Estos factores, todos juntos, identificables tanto como pobrezas culturales como materiales, empujan a las familias a buscar para sus hijos otros caminos, uno de los cuales puede ser la inserción precoz en el mundo del trabajo, esperando asegurar para los niños una profesionalidad que la escuela no garantiza o, en situación de fracaso escolar, de responsabilizarlos, dirigiendo sus intereses hacía otros empleos.

Por otro lado no hay que olvidar que para las generaciones anteriores el trabajo ha sido un importante "maestro de vida", además de ser el presupuesto necesario para la liberación de condiciones de gran pobreza. La familia, pues, guarda la capacidad de condicionar y afectar las referencias de los valores culturales para las nuevas generaciones $\mathrm{y}$, en este sentido, de transmitir la idea del trabajo como valor, siempre y a pesar de todo. 
Es comprensible, entonces, que frente a situaciones problemáticas, la inserción laboral precoz se considera como respuesta útil y eficaz.

No sorprende que la orientación positiva hacia el trabajo emerja principalmente en situaciones de crisis económica con fuertes tasas de desempleo. El trabajo viene en consecuencia enfatizado no sólo como fuente de satisfacción y enriquecimiento sociocultural para el individuo, sino también como valor en sí mismo y herramienta para garantizar una renta mínima siempre más necesaria (más aún con referencia al gradual desajuste de las políticas sociales y a las situaciones derivadas de incertidumbre económica y social).

También hay que tener en cuenta que un empuje hacia una inserción precoz puede derivar de una fuerte orientación positiva hacia el trabajo difundido en los contextos de vida, incluso fuera del ámbito familiar (p.e. algunas zonas caracterizadas por un notable crecimiento económico y por una difundida presencia de pequeñas y muy pequeñas empresas o en las áreas turísticas).

Además el trabajo puede ser considerado como un recurso para evitar los riesgos del tiempo pasado a solas, probablemente en la calle, lugar de desviación por excelencia en aquellos contextos en los cuales no estén presentes itinerarios educativos alternativos, y para aquellas familias que no consiguen cumplir con su función de socialización, que viene delegada a otras instituciones, públicas y privadas, que gradualmente la apoyan en sus funciones educativas. Se subraya en estos casos la responsabilidad de la escuela, que no consigue garantizar adecuadas vías de socialización, que no alimenta el deseo de conocimiento, que no está en grado de garantizar itinerarios diferenciados capaces de insistir en las aptitudes individuales y de responder a las necesidades de cada aluno.

Son muchas las investigaciones que, analizando la relación escuela-trabajo, indican una estrecha conexión entre fracaso escolar e inserción laboral precoz.

31 En la mayoría se confirma la existencia de un proceso circular : en el momento que las dificultades escolares son anteriores a la elección del trabajo, y no al revés, igualmente la actividad laboral influye sobre el rendimiento escolar aumentando las dificultades. investigaciones más recientes, a la dimensión social en su complejo : a la escuela, a la familia, al mercado laboral, a la falta de recursos, a los nuevos desafíos de la complejidad, al crecimiento y a la necesidad de formación, a la cultura del trabajo, al territorio y al propio ambiente de vida. La evolución de las instituciones formativas (de formación), del mercado laboral y de consumo, de los modelos culturales relacionados con la estratificación social y de las distintas áreas, acaba por condicionar las dinámicas de trabajo de chicos y chicas, dentro de una perspectiva de desarrollo contradictorio de una sociedad industrial adelantada (avanzada, NT) que deja convivir vieja y nueva pobreza, viejas y nuevas necesidades, originando estrategias de reacción variadas.

Las formas más graves de trabajo de menores todavía no han desaparecido del todo. Estas desgraciadamente permanecen, pero son probablemente asociables a condiciones de marginación anteriores a la actividad laboral del menor y afectan una parte mínima de la población. Preguntarse sobre el trabajo de menores significa considerar un más amplio abanico de posibilidades y comprender, o decidir, por cada contexto social, de que tipo de trabajo de menores se está hablando. 


\section{El trabajo de menores en los países desarrollados : los países de la Unión Europea}

\section{PORTUGAL}

El trabajo de menores existe en Portugal y está concentrado en las áreas del Norte del país (ICTFU, 2002) en particular en Braga, Oporto y Aveiro. Los menores son a menudo empleados en el pequeño comercio en actividades que piden poca experiencia y generalmente remunerados según el trabajo llevado a cabo. Los sectores más implicados son las obras de la calle, el turismo, y el sector textil. Destaca la presencia de menores también en la agricultura, en el comercio y servicios domésticos, además de las actividades en la calle. Muchos trabajan durante un elevado número de horas que va desde las 10 hasta las 14 horas por día y están también involucrados en actividades ilegales.

El Inspectorado General del Trabajo ha admitido que el trabajo a domicilio afecta los menores y esto complica el trabajo de las inspecciones en el control de las violaciones de la ley en el trabajo de menores. En general, el aumento del desempleo es una de las causas de incremento de trabajo de menores.

Las estadísticas oficiales han a menudo minusvalorado la existencia del trabajo de menores en Portugal, y esto ha producido un largo debate acerca de la forma, las dimensiones y la gravedad del problema, más bien en los sectores económicos importantes como textil, vestuario y zapatos. En 1989 las estadísticas oficiales han señalado 11.486 trabajadores por debajo de los 18 años en estos tres sectores, y en 1991 eran 24719, y además 3834 trabajaban con una edad comprendida entre los 12 y 14 años. En el mismo año un estudio del ILO estimó como 63000 casos de empleados entre 12 y 14 años (Eaton \& Da Silva, 1998), Aunque no oficialmente, el Inspectorado portugués ha admitido que con estas características trabajan 40000 menores, mientras que otros 160000 llevan mucho tiempo haciéndolo (Williams, 1992). Sindicados, iglesia e investigadores independientes declaran que son 200000 los menores de 14 años que trabajan (Williams, 1992 ; Eaton \& Da Silva, 1998). La oposición de los patrones (jefes de trabajo, NT) impide correctas estimaciones (Eaton \& Da Silva, 1998). Las pocas violaciones descubiertas por los inspectores estaban centradas en el sector textil y de vestuario en las regiones del norte del país. Aquí se ha encontrado que la causa principal de trabajo de menores era la pobreza material de las familias (Williams, 1992).

Para determinar la extensión del trabajo de menores por debajo de la edad mínima de los 16 años, en 1998 el Departamento de Estadística para el empleo y la formación profesional del Ministerio Portugués del Trabajo y Solidariedad ha llevado a cabo una investigación sobre 26000 familias. En la investigación destaca que el $4 \%$ de todos los chicos en este grupo de edad trabajaba durante la semana de registro y que el 7,1\% había trabajado durante el año escolar. Muchos trabajos no eran pagados y consistían en actividades de asistencia a familiares, padres $u$ otros mayores en las actividades laborales de venta. De manera que hay más de 1 millones de portugueses con esta edad, la investigación implica que son alrededor de 43077 los chicos que trabajan violando (sin respetar, NT) la ley a lo largo de la semana de evaluación, y 77465 a lo largo del año. Estos números son más bajos de los datos citados por las ONGs. Está claro que, aunque los datos del Ministerio no sean tan modestos como pudieran parecer, de momento son 
una media de distintos grupos de edad, los porcentajes por los chicos de 15 años son aprox. 3-4 veces más grandes.

Actividades económicas con chicos de 6-15 años en Portugal

Actividades económicas con chicos de 6-15 años en Portugal

\begin{tabular}{l|c|c|c}
\multicolumn{1}{c|}{ Sector } & $\begin{array}{l}\% \text { de la fuerza tra- } \\
\text { bajo entre 6-15 } \\
\text { años }\end{array}$ & $\begin{array}{c}\% \text { que trabaja } 5 \\
\text { 0 más dias por } \\
\text { semana }\end{array}$ & $\begin{array}{c}\% \text { que trabaja 4 } \\
\text { horas al dia }\end{array}$ \\
\hline Agricultura & 55.7 & 57 & 34 \\
\hline Artesanía & 12 & 80 & 72 \\
\hline Hostelería & 10,5 & & 84 \\
\hline Comercio & 9,9 & & \\
\hline Construcciones & 6.4 & 70 & \\
\hline Otros sectores & 5,5 & &
\end{tabular}

Fuente: Ministerio del trabajo y de la solidariedad. Plan para la eliminación del trabajo de menores, 2000.

Aunque los datos recogidos por la investigación no permiten conclusiones precisas, se puede afirmar que muchos estudiantes trabajan, una minoría estudia, pero los análisis oficiales de la investigación no profundizan las causas. Parece que, de toda forma, la falta de atractivo de la escuela, más allá de la necesidad o el deseo de trabajar, está en la base del fenómeno. El 56,2 \% de los chicos que deja con antelación la escuela declara que "la escuela no le gusta" como motivación primaria para la inserción en el mundo del trabajo. Sólo el 13,4 \% habla del trabajo. Además, la mayor probabilidad de empleo juvenil está asociada con la baja renta familiar. Esto confirma que Portugal puede corresponder a lo que se define como la "trampa del trabajo de menores" (Basu, 1999) con bajas rentas de las familias como causa de ingreso precoz de menores en el trabajo, dañando su instrucción.

\section{ITALIA}

El ISTAT (Agencia Estadística Italiana, NT) estima que haya más de 145000 menores involucrados en trabajo precoz y no garantizado (excluyendo de este cálculo los menores inmigrantes y Rom (gitanos, NT). Un número enorme, que se sitúa por encima de la media de la Unión Europea (1,5 \%, inferior sólo a Grecia y España del sur), y por encima de la media de los principales Países Occidentales (2\%, según datos ILO). Además, Italia está en segunda posición, dentro de Europa, por el más alto porcentaje de menores que vive bajo el umbral de pobreza. El $17 \%$ de menores en Italia es pobre ; en el Sur el porcentaje llega a 29,1\%. En el panorama general de la pobreza, el grupo de edad hasta los 18 años es el más pobre junto a los mayores de 65 años. Estos datos alarmantes sitúan la pobreza de menores entre los problemas cruciales de nuestro país, porque en ausencia de políticas dirigidas a la inclusión social que sean centradas en la formación escolar y profesional, los menores pobres hoy en día están destinados a quedarse pobres por toda su vida. Entre los niños de 7-10 años que trabajan, más del $80 \%$ de estos viene de familias por debajo o en los límites del umbral de pobreza; el 
90 \% DE ESTOS NUCLEOS FAMILIARES estaría dentro de los límites mínimos, para tener derecho a una renta mínima de inserción. del $40 \%$ de los chicos entre 13 y 15 años trabajan part-time no oficialmente y a menudo ilegalmente. Un número de menores incluido entre un tercio y la mitad de los chicos en edad escolar están empleados en alguna forma de trabajo remunerado. Traducido en términos numéricos significa entre el 1.1 y 1.7 millones de menores en edad escolar, pudiéndose afirmar que el trabajo es la mayor experiencia del menor (Lavalette, Hobbs, Lindsay \& Mckechnie, 1995) y que la experiencia de trabajo remunerado representa un estándar de desarrollo de la adolescencia (Mortimer \& Finch, 1996). Un estudio del Nordeste de Inglaterra del Low Pay Unit ha encontrado que el $44 \%$ de menores trabajadores ha tenido un accidente laboral y que alrededor de un cuarto de menores tenía menos de 13 años. Según la UNICEF el desarrollo del sector de los servicios y la 
demanda de fuerza de trabajo flexible ha contribuido a la expansión del trabajo de menores en Inglaterra.

Otros estudios confirman la ilegalidad del fenómeno y hipnotizan que la mayoría de menores trabajadores sea ilegal (Hobbs \& McKechnie, 1997); en una nota de 1995 del General and Municipal Boilemakers Union (Rikowski \& Neary, 1997) se han encontrado altos porcentajes de menores trabajadores; otro estudio (Gardiner, 1995) cita un análisis sobre 1600 estudiantes de la escuela secundaria de Londres de la cual resulta que el $41 \%$ ha trabajado y entre estos mas del $78 \%$ ilegalmente.

Aún hay que decir que el trabajo ilegal puede ser un trabajo en el cual no se respetan las normas de trabajo, como trabajo no registrado. Esto afecta la posibilidad de dividir la ilegalidad en categorías formales y efectivas, que es el punto de partida y el objetivo del sistema de registro en Reino Unido.

Según algunos estudios llevados acabo en los últimos 10 años el $40 \%$ de menores de edad comprendida entre 13 - 15 años están empleados en actividades part-time ilegales. El $44 \%$ de los niños trabajadores ha sido victima de accidentes laborales y un cuarto de ellos tiene menos de 13 años (ICTFU, 2002).

El trabajo de menores ha llegado a ser una parte importante de la economía de baja renta en Reino Unido. La legislación prohíbe el empleo de menores de 13 años pero, un estudio puesto en marcha por Trade Union Congress, llamado "Working classes", ha encontrado que alrededor de un cuarto de los chicos entre 11-12 años trabaja de forma ilegal.

50 Más de un cuarto de menores que trabajan durante el año escolar declaran trabajar en casa. Muchos trabajan antes de las 7 de la madrugada y a menudo después de las 19 de la tarde.

51 Trabajan toda la semana y a menudo más de tres horas al día. Durante los días de fiesta una pequeña parte trabaja desde 31 hasta 40 horas semanales y más del $3 \%$ trabaja más de 40 horas.Según la Low Pay Unit la exploración de menores esta aumentando en el Nordeste de Inglaterra. El estudio denominado "Fair Play for Working Children" subraya la extensión del fenómeno y las condiciones en las cuales los menores trabajan. El $10 \%$ de los menores de 10 años trabaja, y este porcentaje sube a $35 \%$ para los chicos de 15 años. De los menores que trabajan el $25 \%$ resulta estar bajo el límite legal de edad de 13 años y algunos trabajan más allá de las 29 horas a la semana.

52 Alrededor del $44 \%$ de menores trabajadores ha padecido un accidente durante el trabajo y una décima parte de los accidentes son graves. En 1997-98 Health and Safety Executive declara que el $46 \%$ de menores en edad escolar ha padecido accidentes laborales aunque no haya estadísticos oficiales que reconduzcan este dato a la ilegalidad del trabajo.

Un aspecto interesante que acomuna el fenómeno del trabajo de menores en Reino Unido con lo que se da en los demás países europeos es la modificación de los sectores que piden mano de obra de menores. Trabajan principalmente en la hostelería, en el comercio y venta en la calle (Hibbet \& Beatson, 1995). Se ha destacado también como el trabajo de menores es empleado en actividades rechazadas por los adultos, en particular mujeres, como el trabajo en las cocinas, limpieza en las tiendas y pisos (MacLennan, Fitz \& Sullivan, 1985). Para UNICEF la expansión del sector terciario y la demanda flexible de fuerza de trabajo ha contribuido a la expansión del fenómeno. Según el informe del Consejo de Europa del 1997, alrededor del 50 \% de los niños de 
edad incluida entre 13 - 15 años está empleada en trabajos part - time y la mayoría de ellos trabaja ilegalmente llevando a cabo alguna actividad sin ninguna garantía y con riesgo de explotación. La pobreza de las familias y la renta derivada del trabajo de menores es una de las causas del fenómeno y además también la prostitución de menores es un grave problema cuya difusión constituye una alarma social. Se puede considerar el menor que trabaja como una nueva categoría atractiva para muchos jefes de trabajo que operan en los sectores de trabajo intensivos con bajo capital.

Para otros investigadores mas allá de la causa económica y de la pobreza de las familias que empujarían al trabajo precoz y de consecuencia a integrar la renta familiar (Hobbs \& McKechnie, 1997), el trabajo de menores se caracteriza también por la presencia de menores que trabajan a cambio de dinero para satisfacer propias necesidades materiales, para cumplir con una demanda de consumo basada en un verdadero mercado orientado hacía los menores (White, 1996).

\section{HOLANDA}

Aunque los estudios sobre el fenómeno son escasos, probablemente las estadísticas presentes en la primera tabla general son minusvaloradas. Un estudio del 1987, llevado por el Ministerio del Welfare (White, 1994) ha interesado 20 escuelas y ha destacado que 3/4 de los chicos entre 13-17 años trabajaba por dinero y que entre estos, 3/4 estaba trabajando ilegalmente. La media del horario de trabajo semanal era de 17,4 horas (Hobbs, McKechnie, 1997).

\section{ALEMANIA}

57 Alemania informa una baja tasa de empleo juvenil, aunque no se sabe cuantos chicos alemanes trabajan fuera del sistema de fiscalía oficial. Un análisis llevado a cabo sobre 2500 estudiantes de la escuela superior en Thuringen, p.e., ha encontrado que el $37 \%$ de ellos eran empleados en actividades laborales y el $24 \%$ sin respectar las leyes sobre la edad mínima (German \& Bundestag, 2000). Hay que decir que este análisis, aunque sea recién hecho, ha sido llevado a cabo en el sector agrícola de la ex Alemania del Este, donde el mercado del trabajo probablemente no está registrado. El reciente informe de la Bundestag confirma que los datos existentes acerca del trabajo de menores no son fiables y no ofrecen indicaciones del nivel de desconfianza.

En cuatro estudios realizados en Alemania en los Años 1989, 1993 y 1994 comisionados por los gobiernos regionales de Nordrhein-Westfalen (NRW), Hessen, Brandeburgo y Berlin, sobre un grupo diana de adolescentes entre 12 y 17 años, representantes de la población residente de este grupo de edad (con una mayor concentración en el grupo 13-15 años), se nota que los chicos empiezan a trabajar entre 12 y 14 años en un número significativo, y que también la motivación mas frecuente es la de ahorrar dinero (entre el $66 \%$ y el $72 \%$ de los entrevistados, según el estudio), sea para comprar cosas que los padres no quieren o no pueden adquirir, sea para disponer de ahorros. Normalmente el ahorro no se da en función de un futuro lejano, más bien sirve para comprar objetos de un cierto valor como p.e. un ordenador, un aparato de música, un teléfono móvil. 


\section{ESPAÑA} empleados en trabajo remunerado, por un total de $0,65 \%$ de la fuerza de trabajo. Mientras que este total parece más bajo que la tasa real de actividad, la composición por sectores parece más precisa.

\% de menores de 18 años que trabajan frente al total de la fuerza de trabajo en Francia

$\%$ de menores de 18 años que trabajan frente al total de la fuerza de trabajo en Francia

\begin{tabular}{l|c} 
Sector & \% relativo \\
\hline Alimentación y agricultura & 4,3 \\
\hline Construcciones ediles & 2,8 \\
\hline Venta y reparación coches & 4,3 \\
\hline Hostelería & 3,6
\end{tabular}

Fuente: Institut National de la Statistique et des Études Économiques, 1998

Los menores se requieren más bien en actividades comerciales sub contratadas como la industria de zapatos y en las empresas de gestión familiar (tiendas, bares, trabajos agrícolas (mercados en la calle). En el $51 \%$ de los casos estudiados la motivación que empuja los menores a trabajar es su contribución a la renta familiar. En el 14,4 \% de los casos son los padres mismos que empujan los menores hacia el trabajo. Muchos de ellos empiezan a trabajar antes de los 10 años y alrededor de $1 / 3$ de ellos entre los 11 y 14 años (ICTFU, 2002). El trabajo de temporada esta difundido.

población entre 16-19 años en el 1999 (Instituto Nacional de Estadística, España, 2000), sin tener en cuenta los trabajadores menores de 16 años. Dos publicaciones valoran que en este grupo un número entre 300000 y 500000 (McKechnie \& Hobbs, 1998), mientras que serian 200000 los jóvenes por debajo de los 14 años empleados en el sector informal (Cecchetti, 1998).

\section{FRANCIA}

en particular en el sector informal y en el trabajo de calle, en la distribución de publicidad. Para el sindicado CFDT (Confèdèration française démocratique du travail), no existe una legislación sobre la edad mínima de empleo en los trabajos de hogar, los menores en el sector de la agricultura, pueden trabajar con 12 años bajo el control de sus padres, y resultan también inadecuadas las normas del empleo de menores en el mundo del espectáculo. (ICTFU, 2002).

Los datos estadísticos oficiales pertenecen al Instituto nacional de estadística y de estudios económicos (INSEE). En 1998 se estiman 129155 menores por debajo de 18 años

Che: Institut National de la Staistique et des ttudes tconomiques, 1998

63 Es interesante destacar que el informe INSEE faculta datos acerca de los permisos de trabajo para los jóvenes en la industria de la moda y espectáculo. Esta tipología de actividad se da en todos los países, pero pocos la tienen en cuenta para evaluar su dimensión. En Paris, en 1998, estaban activas 15 agencias para la autorización en 
actividades de chicos como modelos. Aprox. 13500 estaban empelados, pero solo el $20 \%$ de estos regularmente. Además 5268 permisos han sido facilitados a chicos por actividades profesionales en el espectáculo en aquel año en Paris, y muchos en otras regiones del país. Desde este punto de vista Francia puede ser considerada un interesante punto de observación para investigaciones futuras acerca de la situación de jóvenes y en algunos casos de niños, que trabajan en este sector.

\section{DINAMARCA}

Dinamarca es el primo entre los países, como aparece en los datos del OECD (Organisation for Economic Cooperation and Development), inherentes el empleo laboral de jóvenes. Un estudio del 1993 realizado por el Instituto nacional danés de investigación social (Fredeiksen, 1999), encuentra una significativa participación de los chicos, como se puede ver en la tabla.

Participación de chicos en la fuerza de trabajo en Dinamarca, 1993

\begin{tabular}{l|c}
$\begin{array}{l}\text { Participación de chicos en la fuerza de trabajo en } \\
\text { Grupo de edad }\end{array}$ & $\begin{array}{c}\text { Dinamarca, } \mathbf{1 9 9 3} \\
\text { \% que trabaja }\end{array}$ \\
\hline 10 años & 7 \\
\hline 12 años & 18 \\
\hline 14 años & 43 \\
\hline 15 años & 59 \\
\hline $16-17$ cursos profesionales & 44 \\
\hline $\begin{array}{l}16-17 \text { años en la escuela secundaria } \\
\text { (inferior) }\end{array}$ & 64 \\
\hline $\begin{array}{l}16-17 \text { años en la escuela secundaria } \\
\text { (superior) }\end{array}$ & 70 \\
\hline \begin{tabular}{l} 
Total \\
\hline
\end{tabular} & 40
\end{tabular}

Fuente: Frederiksen, 1999

65 La participación total del $40 \%$ ha sido aplicada al grupo entero de 10-17 años. Como en Reino Unido y EEUU (estados unidos), la mayoría de los chicos trabaja desde un mínimo de 1 hora hasta un máximo de 10 horas por semana, pero más de un tercio de estos en la edad entre 15-17 años ha tenido semanas laborales con horarios de trabajo superiores.

\section{GRECIA}

A menudo la ley sobre el trabajo de menores no es respectada. Según el censo del 1991, solamente el 1,3\% de los chicos griegos en edad entre 10-14 años trabaja en un empleo remunerado y esto además es verdadero solo para el 14,3\% de los chicos entre los $15 \mathrm{y}$ 19 años (National Statistical Service of Greece, 2000). Este segundo porcentaje baja hacia el $9 \%$ al final de los años 90 según las estadísticas oficiales. Desafortunadamente, estos números vienen directamente de los registros oficiales de las oficinas de empleo 
pero es posible que en Grecia, como en otros lugares, la mayoría de los jóvenes trabaje fuera del sistema de control.

La distribución del empleo juvenil en los distintos sectores en Grecia muestra el patrón observado en los países en desarrollo. En seguida hay una síntesis de los datos del 1996 del Servicio Nacional de Estadística.

Sectores de empleo de jóvenes en Grecia ( \% sobre total del empleo laboral juvenil)

\begin{tabular}{|c|c|c|c|c|c|c|}
\hline & $\begin{array}{l}\text { Chicas } \\
14 \text { años }\end{array}$ & $\begin{array}{l}\text { Chicos } \\
14 \text { años }\end{array}$ & $\begin{array}{c}\text { Chicas } \\
15^{-19} \\
\text { años }\end{array}$ & $\begin{array}{c}\text { Chicos } \\
15-19 \\
\text { años }\end{array}$ & $\begin{array}{c}\text { Total } \\
14 \text { años }\end{array}$ & $\begin{array}{l}\text { Total } \\
15^{-19} \\
\text { años }\end{array}$ \\
\hline Agricultura & 81,7 & 39,4 & 26,7 & 27,1 & 48,0 & 27 \\
\hline Artesanía & 10,2 & 26,2 & 15,7 & 15,9 & 23,0 & 15,8 \\
\hline Construcción & 0 & 7,2 & 0,7 & 15,8 & 5,7 & 9,7 \\
\hline Comercio & 0,0 & 17,6 & 25,1 & 22,4 & 14,1 & 23,5 \\
\hline Hostelería & 0,0 & 6,2 & 9,8 & 9,6 & 5,0 & 9,6 \\
\hline Total & 91,9 & 96,6 & 78 & 90,8 & 95,8 & 85 \\
\hline
\end{tabular}

Fuente: National Statistical Service of Greece, 1998

Los sectores de agricultura, de artesanía y construcciones, son aquellos donde se centra el empleo de menores. Un estudio de la Greek National Foundation for Social Security, de 1996, ha encontrado que el número medio de días de trabajo por persona en las construcciones varía desde $40 \mathrm{~d}$. para los chicos de 13 años, hasta $70 \mathrm{~d}$. para los chicos de 17 años. Como en Portugal, el ingreso en la fuerza de trabajo contribuye de forma determinante a la salida del circuito de instrucción; otro estudio (Cecchetti, 1998) he destacado que más de $1 / 4$ de todos los estudiantes que no han tenido éxito en la instrucción obligatoria, es por causa del trabajo, remunerado o no, que llevan acabo.

\section{REPUBLICA CHECA}

No hay datos fiables. La prostitución de menores está difundida, juntos al trafico de menores con fines sexuales.

\section{ESTONIA}

71 No hay datos de trabajos de menores en Estonia. Una encuesta del 1999 indica que teniendo en cuenta el total de "fuerza trabajo", solo el 0,2 \% tiene que ver con menores de edad comprendida entra 1617 anos.

Otros informes se refieren a menores empleados en el tráfico de la prostitución, de la droga y en 1999 alrededor de 5000 menores han sido encontrados en la calle. Estos números se refieren tanto a los chicos privados de apoyo familiar, como menores que no asisten voluntariamente a las clases. 


\section{HUNGRÍA}

PIP (State Labor Inspectorate), se da un aumento del número de menores que trabaja y en la violación de las normas de trabajo por parte de los jefes de trabajo. Se encuentran menores en el trabajo de pequeños comercios, en agricultura, en los restaurantes. Se da también la explotación sexual, más bien con chicas.

\section{REPUBLICA ESLOVACA}

No hay datos disponibles de trabajo de menores. El tráfico sexual de menores es un grave problema. No hay datos disponibles sobre la frecuencia escolar.

\section{RUMANIA}

81 En general desde un punto de vista cuantitativo no hay datos disponibles de trabajo de menores. En 1997 una encuesta de Save the Children muestra que, entre los menores, el $8,3 \%$ que va a la escuela trabaja principalmente en agricultura con los familiares (Save the Children, 1997)

82 En 2000 según los datos de NACPA (Nacional Authority for Chile Protection and Adoption), hay entre 2500 y 3500 menores en la calle (Zamfir, 2001). Según el estudio sobre los chicos de la calle, el 62,7 \% de ellos abandona la escuela. 

calle $(60 \%)$ : pobreza, conflictos familiares, violencia, y desorganización familiar (el término "family disorganisation" viene empleado por la Nacional Study on Street Children's Situation y se caracteriza por la presencia de estos elementos: familias ilegitimas, familias con un solo pariente a causa de fallecimiento, divorcio, abandono, cárcel, familias donde está presente el alcoholismo o violencia física o psicológica). En otro estudio de 1997 aparece que el $37 \%$ de los menores trabajadores trabaja por necesidad familiar. En concreto por necesidades de tipo alimentar $(80 \%$, Save the Children Rumania, UNICEF, 1997). El $35 \%$ de las chicas es victima de la prostitución y el $20 \%$ de los chicos de pedofilía. Rumania ratificó la Convención ONU sobre los derechos de la infancia el 28 septiembre 1990. formas peores de trabajo de menores n. 182 del 1999 han sido ratificadas respectivamente en el 1975 y 2000. porcentaje de menores en la escuela primaria disminuye desde $97,3 \%$ del 1989 hasta el 61,6 \% del 1998 (UNDP, 1999).

\section{BULGARIA}

La Bulgaria es miembro asociado del ILO/IPEC. En el 2002 adoptó un plan nacional de acción contra las peores formas de trabajo de menores.

En el 2000 el ILO valoró que el $14 \%$ de menores entre 5 y 15 años trabajaba. Son empleados en actividades remuneradas fuera de la familia en los sectores comerciales y de los servicios, de transportes y comunicaciones, de la industria de las construcciones (edilicia) y en agricultura. También se emplean en actividades no remuneradas por necesidades familiares. Están empleados en trabajos gravosos y expuestos a riesgos para la salud en las empresas de tabaco. El $10 \%$ de las prostitutas son menores y se emplean en la industria del sexo las niñas de 12 y 13 años.

\section{Europea.}

\section{TURQUÍA}

El trabajo de menores es un fenómeno estrictamente relacionado con la estructura demográfica del país de referencia, con el sistema educativo, con el nivel de desarrollo económico y social. estadísticos.

91 En el 2000 ILO valoró que el 7,8\% de menores con edad incluida entre 6 y 14 años ha sido empleado en trabajos de agricultura, oficinas, carpintería, industrias textiles, peletería (industria de pieles) y servicios del hogar. Según una encuesta de 1999 el 4,2 \% de los niños de edad incluida entre 6 y 14 años resultan económicamente activos (511000), mientras el 27,6\% (3329000) están empleados en trabajos de hogar (World Bank, 2002). 

(1999) han sido implicadas 17978 familias de 167 ciudades y 5211 familias de 250 de zonas rurales. La encuesta ha analizado el fenómeno a partir de dos categorías de análisis : los menores empleados en actividades económicas y los menores empleados en actividades domésticas.

Tipo de trabajo de menor - por género y área

Tipo de trabajo de menor - por género y área

\begin{tabular}{|c|c|c|c|c|c|}
\hline \multirow{2}{*}{$\begin{array}{c}\text { Residencia } \\
\text { edad } \\
y \\
\text { género }\end{array}$} & \multirow{2}{*}{$\begin{array}{c}\text { Total } \\
\text { Minores }\end{array}$} & \multicolumn{3}{|c|}{ Trabajando } & \multirow{2}{*}{$\begin{array}{c}\text { No } \\
\text { Trabajando }\end{array}$} \\
\hline & & Total & $\begin{array}{l}\text { En } \\
\text { actividad } \\
\text { económica }\end{array}$ & $\begin{array}{c}\text { Trabajo } \\
\text { domestico }\end{array}$ & \\
\hline $\begin{array}{c}\text { Turquia } \\
\text { Total }\end{array}$ & 16088 & 6420 & 1635 & 4785 & 9668 \\
\hline Hombres & 8202 & 2300 & 1290 & 1290 & 5903 \\
\hline Mujeres & 7885 & 4121 & 625 & 3496 & 3765 \\
\hline $\begin{array}{c}\text { Área urbana } \\
\text { Total }\end{array}$ & 9577 & 3626 & 552 & 3074 & 5951 \\
\hline Hombres & 4926 & 1352 & 415 & 937 & 3575 \\
\hline Mujeres & 4650 & 2274 & 138 & 2137 & 2376 \\
\hline $\begin{array}{c}\text { Área rural } \\
\text { Total }\end{array}$ & 6512 & 2795 & 1083 & 1712 & 3717 \\
\hline Hombres & 3276 & 948 & 596 & 353 & 2328 \\
\hline Mujeres & 3236 & 1847 & 487 & 1359 & 1389 \\
\hline
\end{tabular}

Fuente: State Institute of statistics international, 1999

\section{El trabajo de menores en los países de la Unión Europea : algunas reflexiones}

La explotación de menores en el trabajo es un problema existente en la Unión Europea, así como en el resto del mundo. El fenómeno del trabajo de menores, en los diferentes países europeos, no ha sido profundizado y se da la necesidad de investigar cuidadosamente el problema. En general las leyes sobre trabajo de menores y la presencia de la obligación escolar muestran como menos difundido el fenómeno en el Norte de Europa.

98 A partir de las valoraciones referidas es probable que más de la mitad de chicos por debajo de los 18 anos se emplee como "fuerza trabajo" en cada país desarrollado. En los 
países donde hay datos más detallados, los chicos empiezan a trabajar a la edad de 15 anos, aunque el tipo de trabajo cambie con su desarrollo. Con excepción de EEUU, donde no hay un sistema nacional de registro del fenómeno, la mayoría de los jóvenes que trabajan son ilegales y hasta en Estados Unidos la ilegalidad es muy difundida. Esta constante infracción a la ley sobre el trabajo de menores es uno de los aspectos más interesantes del fenómeno.

Los países del Sur de Europa (Portugal, España, Italia y Grecia) presentan un modelo de empleo que se parece en algunos aspectos en aquello de países en desarrollo, con los chicos empleados en gran cantidad en algunas actividades como zapatería, vestuario, los sectores textiles y artesanías, el sector de la construcción y agricultura. La privación económica no parece ser la causa predominante del empleo juvenil en el mercado del trabajo, aunque la presión de la pobreza de las familias juegue un rol importante en el sur de Europa.

El tema del trabajo de menores esta estrictamente relacionado con aquello de la economía del "trabajo sumergido". El problema implica, a distintos niveles, todos los países OCSE. Italia, con una economía sumergida evaluada por la Comisión entre el $20 \%$ y el $26 \%$ del PIB (producto interno bruto, NT), cubre la segunda plaza en el listado europeo, adelantada solo por Grecia (29\% 35 \%). El Sur de Europa (Italia, Grecia, España, Portugal) es la área que registra la mayor presencia y difusión de una economía de tipo sumergido, y si esta guarda una relación con el trabajo de menores podemos colocar la hipótesis de una fuerte presencia de mano de obra de menores en toda la área mediterránea, en particular Grecia, España, Italia, Portugal y en alguna medida también Francia. Esto obviamente no significa que en otros países el fenómeno no esté presente. Es más, en los países del Norte de Europa, como p.e. Gran Bretaña, el trabajo de menores esta documentado ; lo que significa que analizando la presencia del trabajo de menores en una determinada área geográfica, el indicador representado por el tipo de mercado del trabajo es solo uno, aunque sea importante, entre todos los indicadores que se deben tener en cuenta.

\section{Discriminación de género y estadísticas}

Un elemento sobre el cual reflejar atentamente esta constituido por un análisis de género de los datos estadísticos.

Según los datos ILO en la mayoría de los países los menores de sexo masculino son por mayoría empleados en actividades laborales, con respecto a las chicas de la misma edad. En concreto, el $27 \%$ de los chicos entre 5 y 14 anos son económicamente activos, contra el 22,3\% de las chicas (ILO-IPEC, 2002). 


\begin{tabular}{|c|c|c|c|}
\hline Grupo de Edad & Total & Hombres & Mujeres \\
\hline $5-10$ años & 73,1 & $38,1(52,2 \%)$ & $35,0(47,8 \%)$ \\
\hline 10-14 años & 137,7 & $70,9(51,5 \%)$ & $66,8(48,5 \%)$ \\
\hline 15 -17 años & 140,9 & $75,1(53,3 \%)$ & $65,8(46,7 \%)$ \\
\hline \multicolumn{4}{|l|}{ Fuente: ILO/IPEC 2002} \\
\hline \multicolumn{4}{|c|}{$\begin{array}{l}\text { Valoración global de menores económicamente activos de edad incluso entre 5-17 anos en el } \\
200 \text { por edad y género }\end{array}$} \\
\hline Edad y Sexo & $\begin{array}{l}\text { Población Total } \\
\times 1000\end{array}$ & $\begin{array}{c}\text { Trabajadores } \\
\mathrm{x} 1000\end{array}$ & $\%$ Trabajadores \\
\hline \multicolumn{4}{|l|}{ Hombres } \\
\hline $5-9$ años & 308.500 & 38.100 & 12.3 \\
\hline $10-14$ & 307.900 & 70.900 & 23.0 \\
\hline 5-14 & 616.400 & 109.000 & 17.7 \\
\hline $15-17$ & 170.200 & 75.100 & 44.0 \\
\hline Total & 786.600 & 184.100 & 23.4 \\
\hline \multicolumn{4}{|l|}{ Mujeres } \\
\hline $5-9$ años & 291.800 & 35.000 & 12.0 \\
\hline $10-14$ & 291.300 & 66.800 & 22.9 \\
\hline 5-14 & 583.100 & 101.800 & 17.5 \\
\hline $15-17$ & 161.800 & 65.800 & 40.7 \\
\hline Total & 744.900 & 167.600 & 22.6 \\
\hline \multicolumn{4}{|l|}{ Total $\mathrm{H}+\mathrm{M}$} \\
\hline 5-9 años & 600.200 & 73.100 & 12.2 \\
\hline $10-14$ & 599.200 & 137.700 & 23.0 \\
\hline 5-14 & 1.199 .400 & 210.800 & 17.6 \\
\hline $15-17$ & 332.100 & 140.900 & 42.4 \\
\hline Total & 1.531 .100 & 351.700 & 23.0 \\
\hline
\end{tabular}

En la relación menor-trabajo podemos encontrar que un menor se clasifique como "trabajador" si es activo económicamente. La distinción ILO entre "child work" y "child labour" (en principio desarrollado por IWEGCL - International Working Group on Child Labour), intenta dicotomizar la lectura del fenómeno por el cual el trabajo ligero esta asociado al trabajo en familia y presenta algunos valores positivos (ILO, 1996), mientras que el trabajo gravoso esta asociado al trabajo por otros y a la explotación. Esta visión no es correcta si se adopta en el análisis del trabajo de menores en países desarrollados. En los párrafos siguientes se profundizara el concepto de "económicamente activos".

La categoría económicamente activa esta asociada en la mayoría de los casos al sexo masculino. De hecho, si los datos excluyen el trabajo doméstico en cuanto no económicamente activo, un porcentaje elevado esta excluido por las valoraciones. Este es el caso del trabajo de cuidado, del trabajo doméstico, es la diferencia entre trabajo proyectado hacia el interior que prima el empleo de chicas y el proyectado hacia el exterior que, en cambio, se da predominantemente con chicos. Muchos estudios llevados a cabo en los países en desarrollo confirman esta tendencia (Cochrane, Kozel \& Alderman, 1990).

Otro aspecto es el relacionado con la diferencia de género con respeto a la formación e instrucción. Destaca una disparidad interesante entre los estudios del fenómeno en los países en desarrollo y aquellos hechos en Occidente. En los PVS (países en desarrollo) el trabajo de menores (económicamente activo y no) para las chicas conlleva un abandono del recorrido formacional-educativo particularmente pesado y, en general, las familias no invierten dinero en la instrucción para sus hijas. La situación presenta una tendencia opuesta en los países industrializados entre los cuales se da por mayoría el abandono escolar precoz del menor de sexo masculino. En occidente son más altas las 
tasas de fracaso de los chicos, mayores los abandonos, menor el beneficio escolar. Las chicas consiguen resultados más brillantes y siguen los estudios por más tiempo.

Actividades Remuneradas No remuneradas

\begin{tabular}{l|l|l} 
Actividades & Remuneradas & No remuneradas \\
\hline Domesticas & Trabajo a domicilio & $\begin{array}{l}\text { Colaboración en la gesti- } \\
\text { ón de la casa, cuidado de } \\
\text { hermanos menores y an- } \\
\text { cianos. }\end{array}$ \\
\hline Extradomesticas & $\begin{array}{l}\text { Trabajo con salario, tra- } \\
\text { bajo precario pero repeti- } \\
\text { do en el tiempo }\end{array}$ & $\begin{array}{l}\text { Trabajo en empresa fami- } \\
\text { liar, voluntario o impues- } \\
\text { to por otros; limosna }\end{array}$
\end{tabular}

106 La lectura de la tabla destaca la diferencia de género. Niñas y chicas son empleadas principalmente en actividades domésticas remuneradas y no remuneradas. Se caracterizan como "femeninos" todos los trabajos de cuidado de los espacios domésticos y de las personas que viven en casa: hermanos, hermanas más pequeñas, discapacitados y ancianos. Pero las niñas y chicas pueden, en el mismo tiempo, ser empleadas también en actividades extra-domésticas de ayuda puntual o prolongada en actividades agrícolas o comerciales. A estas se van sumando otros "empleos", como la limosna o el comercio sexual, desde la pornografía a la prostitución.

107 A menudo en las encuestas sobre trabajo de menores no se consideran aquellas actividades que, aunque sean desempeñadas por menores, no presentan una retribución económica. Las niñas y chicas que, siendo empleadas por muchas horas en actividades de ayuda doméstica, tienen menos tiempo de dedicar al estudio, al juego, a las relaciones con el grupo de iguales, viven a todos los efectos una situación de "explotación", aunque el objetivo sea ayudar la familia, no haciendo parte de ningún tráfico y sin animo de lucro. Las escuelas deberían estar capacitadas para prevenir, registrar y contrastar fenómenos de este tipo desarrollando formación a los adultos y actividades de información sobre las leyes existentes y fondos nacionales y regionales para las políticas sociales. De hecho, más bien en las pequeñas comunidades agrícolas podemos encontrar menores empleados en trabajos relacionados con actividades de empresas de gestión familiar en el sector primario (agricultura y crianza de animales), y en el comercio fijo y ambulante.

108 Según la edad varían pues las características de las incumbencias confiadas, que aumentan en complejidad, y varía también el tipo de empleo en la actividad laboral: saltuario para los más pequeños, de temporada de verano para determinados tipos de estudiantes (en particular aquellos que vienen de institutos profesionales para servicios de hostelería), continuado para los mayores. Algunos consiguen conciliar el trabajo con el estudio, otros se alejan gradualmente de la escuela hasta abandonarla.

109 La variable de género influye sobre la variable de tiempo : seguramente la tipología del trabajo doméstico es aquella que involucra niñas y chicas para todo el año y puede emplearlas para un número de horas diarias bastante relevante. Es interesante notar cómo, desde las encuestas sobre el tiempo libre desarrolladas recientemente en algunos institutos escolares (nos referimos a una encuesta llevada a cabo en el 2003 en algunas escuelas de la provincia de Catanzaro en Italia), resulta que las chicas dedican menos tiempo a la ayuda doméstica respecto al pasado y que, en media, el tiempo dedicado en 
actividades domésticas corresponde a aquello dedicado a las mismas actividades por los chicos.

110 Existe también una analogía de ocupaciones : quitar la mesa, fregar y barrer, ayudar los más pequeños con los deberes o llevarlos de paseo. Son una excepción los casos de chicas que tienen a su cargo el núcleo familiar, a las cuales corresponde la excepción de los chicos que pasan hasta siete horas diarias en el campo empleados en actividades agrícolas. A menudo las chicas han escrito que trabajan en casa por un número de horas improbable. Quizá la tendencia a inflar el dato (darle mas importancia, NT) se debe atribuir al hecho de que se trata de una actividad que no gusta, vivida como un peso, y en este caso el tiempo sujetivo prevale sobre el objetivo.

111 Otra tipología muy particular de trabajo de menores es aquella relacionada al mundo del espectáculo que quizá no se considera como explotación, en el momento que ofrece una visibilidad positiva hacia el externo, y también porque la ganancia es consistente, finalmente porque no comporta un gran esfuerzo físico. Pero todo esto es verdadero solo si nos limitamos en un análisis superficial del fenómeno.

112 Una visibilidad que permite ser conocidos a través de la cara de un personaje interpretado, que de toda forma no coincide con lo que somos realmente, para un sujeto en desarrollo puede significar un abuso gravoso, de la misma forma que trabajar forzadamente frente a un telar, llegando a dejar trazas profundas en el equilibrio psicofísico. La presencia en el set (escenario cinematográfico, NT), los viajes, las faltas de la escuela, vivir en el medio de adultos que dirigen nuestras acciones y por un tiempo también nuestra vida, puede perturbar el bienestar del niño/a. Esto viene reportado a partir de las experiencia de muchos ex niños-prodigio, que ya en edad muy precoz tienen problemas de droga, alcohol, y llegan incluso a ser padres /madres con matrimonios fracasados en el pasado.

113 Más allá de estos tipos existen aspectos del trabajo de menores que implican comunidades de inmigrantes. Este es el caso de los niños que venden pañuelos y mecheros en las calles, que limpian los cristales en los semáforos, que pasan días enteros de verano recorriendo kilómetros de playa con la esperanza de vender algo. En este caso la variante de género es aun más presente. Las chicas no venden en la calle, ni en las playas, porque por cierto la división de los roles y la relación con el externo prevé su empleo en el hogar.

114 Seria interesante indagar acerca del tipo de vida que estos niños/chicos y sus coetáneas llevan dentro de su comunidad de pertenencia.

115 Todo lo dicho justifica la imposibilidad de enfrentarse con un único enfoque a una multitud de formas. Además se tendrían que eliminar muchos tópicos que todavía influyen mucho en la objetividad científica de los estudios.

116 Es mentira decir que el trabajo de menores existe solo en el Sur y que es exclusivo de las áreas económicamente deprimidas. Es mentira que este se presenta en familias precarias económicamente.

117 Es mentira que donde no se da el abandono escolar no exista el trabajo de menores porque en cambio es siempre más difundida la figura del estudiante-trabajador, más que la del trabajador a tiempo completo. Lo demostrarían datos inherentes a las ausencias al fin del año escolar, por los cuales la mayoría de los estudiantes de Institutos Superiores Profesionales dejan de frecuentar la escuela alrededor de la mitad de mayo porque este periodo coincide con la abertura de la temporada turística. 
118 De momento la existencia del trabajo de menores en los países desarrollados ya no es considerada una expresión de sub-desarrollo, o por la necesidad de sobrevivir, devienen necesarias nuevas modalidades de investigación y un nuevo modelo interpretativo capaces de destacar aspectos de carácter social, económico, cultural, educativo y formativo.

119 Si en el pasado algunas familias podían guiar a sus hijos hacia un camino laboral para garantizarles la adquisición de habilidades practicas, quitarlos de la calle y favorecerle en la socialización en un universo mixto de coetáneos y adultos, hoy en día son los mismos chicos a desear un trabajo para cobrar. Es altísimo el porcentaje de chicos de edad incluida entre 13 y 16 años que tiene su propio teléfono móvil. Son muchos los chicos de edad inferior a 14 años que ya tienen una moto. En esta oferta precoz de bienes inducidos por el mercado probablemente se da una de las causas más recientes de trabajo de menores.

\section{El trabajo de menores y el mercado laboral}

120 El trabajo de menores se sitúa en los huecos de un mercado laboral fragmentado, entre las franjas de la economía informal, más que formal, destacándose bajo la forma de "trabajos" en lugar que de "trabajo", tanto por las distintas actividades que los chicos/ as pueden desempeñar, como por las distintas motivaciones que conllevan una inserción laboral precoz.

121 Por lo tanto se considera equivocada la opinión de quien define la explotación como cualquier situación que ve un menor enfrentarse a una tarea que se desarrolle autónomamente o en ayuda de personas mayores. No se puede decir, de hecho, que cada situación de trabajo sea explotación, pero tampoco, por otro lado, que cada trabajo sea siempre útil y positivamente formativo.

122 Si ponemos el trabajo de menores dentro de un continuo, en el cual por un lado tenemos el trabajo explotado, y por el otro el trabajo que no necesariamente se da como factor no educativo o lesivo para el desarrollo del niño, pues en el medio, tendríamos una vasta área gris (intermedia, NT) constituida por trabajos en los cuales se mezclan factores positivos y negativos.

123 La distinción hoy en día comúnmente empleada entre child work (trabajo no lesivo) y child labour (trabajo explotado), es interesante y contribuye a propulsar el análisis del fenómeno. Todavía hay que tener cuidado en no clasificar como child work exclusivamente los trabajos reproductivos o aquellos desempeñados en ámbito familiar (p.e. dentro de una empresa familiar) y como child labour aquellos desempeñados por cuenta de terceros. Pero no es tan sencillo. Los factores positivos y negativos se entrelazan, no todo aquello que tiene lugar bajo control de la familia es positivo, como tampoco lo que tiene lugar en ámbito extra-familiar, pues por cuenta de terceros, es negativo. El trabajo en el camino hacia la socialización tiene una propia valencia (valor, NT), depende del contexto y del medio vital, de la historia del sujeto, de la de su familia y de la comunidad de pertenencia, y se origina a partir de la relación con las agencias de socialización, depende de las mismas formas con las cuales se lleva a cabo. También depende de la persona que ha elegido el trabajo. Si por un lado, de hecho, existe una oferta de trabajo, existe también una demanda que puede estar de alguna forma inducida, pero puede ser también el resultado de la elección sujetiva o voluntaria del 
chico/a, que es necesario tener en cuenta. Esto implica una serie de cuestiones sobre múltiples aspectos, más que nada acerca de la diferencia entre tener y ejercer derechos, tema que implica en general toda la infancia y que se destaca en este caso cuando ya no se tiene en cuenta el derecho del chico/a para poder expresar su propia opinión o motivaciones sobre el trabajo en el que esta involucrado.

A partir de las imágenes que provienen del mundo adulto ya sabemos alguna cosa. Pero se tendría que escuchar a los chicos/as mismos/as. ¿Qué piensan chicos y chicas del trabajo ?, y más concretamente, ¿qué piensan acerca del propio trabajo desempeñado? Son todavía pocas las investigaciones cualitativas que reportan las opiniones de los directos interesados, pocas las que intentan involucrar chicos y chicas en el esfuerzo de comprender sus motivaciones y problemas relativos. Probablemente hace falta empezar a contemplar las imágenes del trabajo no solo como "mala o equivocada conciencia" y no pensar simplemente en términos de "demandas de educar".

Antes que todo hace falta tener en cuenta todos los significados y motivaciones que conllevan un trabajo precoz, sin reducirlas a un bloque monolítico, cuando en realidad esto no es así.

\section{El trabajo de menores y el contexto escolar}

La relación entre instrucción y trabajo de menores va además considerada a la luz de algunas importantes variables :

- La diferencia de género : implica factores culturales, sociales y económicos que influyen en los distintos tipos de trabajos desempeñados por chicos y chicas.

- Las diferencias territoriales : los datos sobre trabajo de menores y las investigaciones locales tienden a demostrar cuanto las diferencias existentes entre distintos territorios y distintas áreas inciden sobre la oferta de trabajo para menores. Una clara distinción es aquella que se da entre áreas urbanas y rurales.

- La instrucción : la carrera escolar y la calidad de la instrucción son elementos determinantes para el aumento de los conocimientos y centrales en proceso de desarrollo económico. Se asiste en todos los países analizados al retorno de la inversión en la instrucción.

relación entre trabajo de menores y frecuencia escolar se puede hablar de compatibilidad formal y incompatibilidad sustancial. La primera se da a partir de la constatación que aun cuando la actividad laboral adquiere un carácter continuativo, esta cubre un periodo del día que no entra directamente en conflicto con la frecuencia escolar. La segunda destaca claramente una vez tomadas en cuenta: las ausencias ocasionales, el bajo rendimiento, el alto número de alumnos que repiten el año, fenómenos de bulismo (bulling, NT), problemas de tipo disciplinar, déficit de atención.

Los menores empleados en actividades laborales presentan, hacia la escuela, una aptitud general negativa que a menudo es el resultado del escaso valor atribuido a la carrera escolar por la familia. La adquisición de este tipo de conocimientos se percibe como superflua, la consecución de un título de estudio se valora como inútil y, además, la "adultización" precoz crea problemas en las relaciones personales con los "iguales", que acaban teniendo la misma edad solo a nivel anagráfico (cronológico, NT). El menor vive su experiencia escolar sin percibir por completo, o muy limitadamente, la conexión existente entre la función del aprendizaje y la de la socialización. Si por un lado es verdad que la socialización es el resultado de procesos de aprendizaje, de 
lenguajes, de noticias, de proyectos, la escuela representa el medio que, entre todos, favorece tal recorrido. Las dos funciones al contrario vienen vividas, o hechas vivir (impuestas, NT), como separadas, y se identifica por un lado el aprendizaje como contexto no gratificante, y por el otro la escuela como lugar pobre de socialización, al cual se prefiere el contexto extra-escolar. El menor se encuentra por lo tanto en una situación de fragilidad : en una edad de gran importancia para la construcción de una propia identidad, los tres contextos con los cuales interactúa - trabajo y territorio, familia, escuelay que deberían representar puntos de referencia importantes y determinantes en el crecimiento, son vividos como incapaces de relacionarse entre sí. El riesgo es de construir una realidad separada en la cual el vacío de valores viene rellenado con otros valores: el equipo de fútbol, el cantante famoso, la bandilla del barrio, etc., dentro de un proceso de disociación y exclusión preocupante.

El trabajo de menores abre algunas cuestiones no solo acerca de la condición de la infancia y preadolescencia en general, sino también sobre la hipocresía de los Gobiernos que, por un lado, no ponen en marcha políticas miradas de prevención y acciones positivas. Además, por una parte existen niños y preadolescentes sin trabajo, incluso tutelados demasiado y privados de cualquiera responsabilidad, destinados a roles subalternos hasta una edad adulta avanzada, con probables recaídas negativas en la construcción de una personalidad madura.

131 Por otra parte, encontramos niños y preadolescentes obligados a un trabajo precoz, que asumen temprano la responsabilidad de un adulto, con escasa información y poco tiempo libre, por los cuales la actividad laboral deviene un juego cotidiano.

Probablemente ninguna de estas dos condiciones garantiza un crecimiento equilibrado y el ingreso en una vida adulta basado en la adquisición de sólidos componentes. El camino a seguir es quizá mas relacionado a la contaminación entre dos extremos, a la posibilidad de construir itinerarios diferenciados y flexibles en los cuales esté presente una mezcla entre estudio y aprendizaje práctico y se prevean formas de reconocimiento y tutela de las actividades laborales que no resulten nocivas para el desarrollo y el crecimiento de los menores implicados.

Todo esto nos ayudaría a enfrentarnos con mejores herramientas a la diversidad de las experiencias, de los caminos de crecimiento y significados que debemos asignar al trabajo y a la formación. Pero es importante no bajar el umbral de atención (tener en cuenta, NT) de los vínculos ambientales, de las influencias socio-estructurales, del riesgo que la diversidad se transforme en aceptación de la black economy, de lo sumergido (escondido, NT), de la explotación.

134 Seria de hecho la misma atención (pero con alguna energía más) que debemos poner hoy hacía la frágil frontera que separa - también en el mundo adulto - la flexibilidad desde el mercado salvaje. El trabajo de menores se debe por lo tanto relacionar, como todas las más recientes investigaciones ya destacan, a la dimensión social por entero (en su complejo, NT) : escuela, familia, mercado del trabajo, falta de recursos, nuevos desafíos de la complejidad, crecimiento y necesidad de formación, "cultura" del trabajo, territorio y propio medio vital. La evolución de las instituciones formativas, del mercado del trabajo y de los consumos, de los modelos culturales relacionados a la estratificación social y a los distintos territorios, acaba por condicionar también las dinámicas del trabajo de chicos y chicas, en la perspectiva de desarrollo contradictorio de una sociedad industrial avanzada que deja conviviendo viejas y nuevas pobrezas, viejas y nuevas necesidades, originando múltiples estrategias de reacción (Fulciniti, 
2004). Es evidente que en un similar contexto los fenómenos de abandono, de evasión y de fracasos escolares, sean destinados en aumentar. Si la competición y la "elección de la familia" acaban definiendo el "sentido" de la experiencia escolar, el destino social de miles de niños y chicos aparece ya determinado.

\section{BIBLIOGRAFÍA}

Basu, K. (1999). Child Labour : Cause, Consequence and Cure, with Remarks on International Labour Standards. Journal of Economic Literature, 37, 3, 1083-1119.

Cecchetti, R. (1998). Children Who Work in Europe : From Exploitation to Participation. Brussells : European Forum for Child Welfare.

Cochrane, S., Kozel V., Alderman H., "Household Consequences of High Fertility in Pakistan," World Bank Discussion Paper No. 111

Eaton, M. \& Pereira da Silva, C. (1998). Portuguese Child Labour : Manufacturing for Ch'ange or Continuino Exploitation in the Textile Industry? Childhood : a Global Journal of Child Research, $5,3,325-343$.

Fulciniti, P. (2004). La fiaba che non c'è. Valore scuola, 8, 15,17 Frederiksen, L. (1999). Child and Youth Employment in Denmark : Comments on Children's Work from Their Own Perspective. Childhood, 6, 1, 101-112.

Gardiner, J. (1995). Much Too Early to Be Out Working, The Times Educational Supplement, April 14.

German Bundestag (2000). Bericht der Bundesregierung ueber Kinderarbeit in Deutschland, Drucksache 14/3500, 2 June.

Hibbet, A. \& Beatson, M.(1995). Young people at work, Employment Gazette, April.

Hobbs, S. \& McKechnie, J. (1997). Child employment in Britain. London : The Stationay Office.

ILO (1996). Child labour Today : Facts and Figures, Geneva, ILO

ILO-IPEC (2002) Every child counts. New global estimates on child labour, Geneva, ILO

Instituto Nacional de Estadistica, Spain (2000). Madrid : INEbase.

Institut National de la Statistique et des Études Économiques, France (1998), Labor-force surveys, INSEE, France

ICFTU (International Confederation of Free Trade Unions). Internationally-recognized core labour standards in the 15 member states of the European Union. Geneva, July 2002.

MacLennan, E., Fitz, J. \& Sullivan, J. (1985). Working Children. London : Low Pay Unit, Report n.2

Ministry of Labour and Solidarity, (MTS) (1998). Child Labour in Portugal Social Characterisation of School Age Children and Their Families, Lisboa 
Mizen, P. \& Pole, C. (1998). The Paid employment of children in Britain : sociological themes and issues. Paper to working Group 03, Sociology of Childhood, International Sociological Association World Congress, Montreal, Canada.

Lavalette, M., Hobbs, S., Lindsay, S. and McKechnie, J. (1995) Child employment in Britain : Policy, myth and reality, Youth and Policy, 45,115

McKechnie, J. \& Hobbs, S. (1998), Working Children : Reconsidering the Debates, Amsterdam, International Working Group on Child Labour. National Statistical Service of Greece, (1998), NSSG, Labour Force Survey

Mortimer, J. T. \& Finch, M. D. (1996). Work, Family and Adolescent Development. California : Sage.

Paone, G. (2004). Ad ovest di Iqbal. Roma : Ediesse

Paone, G. \& Teselli, A. (2000). Lavoro e lavori minorili. Roma : Ediesse Rikowski, G. \& Neary, M. (1997). Working Schoolchildren in Britain Today. Capital \& Class, 63, 4, 5-36.

Save the children (1997). Child labor in Romania, 1

Save the Children Romania, UNICEF (1997). Children and Work.

State Institute of Statistics International Republic of Turkey \& ILO (1999). Child Labour in Turkey. UNDP (1999). The National Human Development Report. Bucharest : Romanian Academy.

White, B. (1994). Children, Work and "Children Labour" : Changing Responses to the Employment of Children. Development and Change, 25, 4, 849-878.

White, B. (1996). Globalisation and child labour problem. Working Paper Series n. 221. The Netherlands : Institute of Social Studies.

Williams, S. (1992). Child Workers in Portugal. London : Anti-Slavery International.

World Bank (2002). World development indicators. Washington, D.C. Zamfir, C. (2001). Poverty in Romania : Causes, Anti-poverty policies,

Recommendations for Action. Bucharest : Research Institute for the quality of life.

\section{RESÚMENES}

En Europa la cuestión del trabajo infantil no está muy investigada. El punto de vista de la gente común es que el trabajo infantil ha sido eliminado de nuestras sociedades occidentales.

Pero no es así y sería instructivo mirar con más atención a las formas que asume en los países que son económicamente avanzados.Si nosotros lográsemos comprender e identificar las diferencias y las semejanzas entre los modos en que los diferentes países se aproximan a la condición de la infancia y de la adolescencia, nosotros estaremos en grado de echar las bases para las futuras estrategias, las futuras políticas y los planos de acción para excluir las desigualdades, El trabajo infantil es también una importante cuestión en los países industrializados. El trabajo infantil penetra en los intersticios de un mercado del trabajo fragmentado y es más predominante en los diferentes sectores de la economía informal. En los países europeos un número mas grande de niños trabaja para una paga en ocupaciones de temporada, comercio de calle y trabajo domestico por ejemplo. La transición de algunos países de Europa hacia la economía de mercado ha determinado un empeoramiento del trabajo infantil en Europa central y del Este. Pero en algunos casos los niños trabajan en parte para sus mismas elecciones. 
Na Europa o trabalho de menores não está investigado em profundidade. A perspectiva do senso comum é de que o trabalho infantil foi irradicado das sociedades ocidentais. Mas não é assim, e seria instrutivo um olhar mais próximo sobre as formas que assume em países economicamente avançados. Compreendendo e identificando as semelhanças e as diferenças entre as formas como diferentes regiões abordam a fase da infância e da adolescência ajudarnos-á a fundar os alicerces de estratégias, políticas e planos de acção futuros para esbater as desigualdades sociais.O trabalho de menores é também uma questão importante num quadro alargado de sectores em países industrializados. O trabalho de menores preenche os interstícios de um mercado de trabalho fragmentado, e é especialmnete prevalente em vários sectores da economia informal. Nos países Europeus, um elevado número de crianças realiza trabalhos sazonais remunerados, vendas de rua e trabalho doméstico, por exemplo. A transição de alguns países da Europa de Leste para uma economia de mercado trouxe também o ressurgimento do trabalho de menores na Europa Central e do Leste. Em alguns casos, no entanto, as crianças trabalham em parte por sua livre vontade, para as suas despesas pessoais.

En Europe le problème du travail des mineurs n'est pas pris en considération d'une manière adéquate. Le point de vue des gens communes est que le travail des mineurs a été vaincu, à leur avis le problème n'existe pas dans nos sociétés occidentales. Mais ce n'est pas comme ça, donc serait intéressant d'observer quelles sont les différentes formes qu'il peut prendre dans les pays économiquement avancés. Il faudrait connaître de quelle façon les différents pays s'approchent à la condition de l'enfance et de l'adolescence pour en identifier et comprendre les différences et les ressemblances. Seulement à ce point là nous serons capables de jeter les bases des futures stratégies, des politiques et des plans d'intervention pour renverser les inégalités. Le travail des mineurs est un problème considérable dans plusieurs secteurs des pays industrialisés. Il pénètre dans les interstices d'un marché du travail fragmenté et il prédomine dans plusieurs secteurs de la soi-disant économie informelle. Dans les pays européens un plus grand nombre d'enfants travaille pour avoir une rétribution en menant des occupations saisonnières ou bien des travaux ménagères ou même en faisant du commerce dans les rues. La transition des pays de Est de l'Europe vers une économie de marché a produit une aggravation du travail des mineurs dans l'Europe centrale et de l'Est. Quelquefois sont les enfants qui décident d'eux-mêmes de travailler pour avoir de l'argent à dépenser.

In Europe child labour is not thoroughly studied or reported. The popular view is that child labour has been eradicated in Western societies. This is not the case, however, and it would be instructive to look more closely at the forms it takes in economically advanced countries. Understanding and identifying the similarities and differences between how the different regions approach the condition of childhood and adolescence will help lay the foundations for future strategies, policies and action plans to erase social inequalities.

Child labour is also a big issue across a very wide range of sectors in industrialised countries. Child labour fills the interstices of a fragmented labour market, and is especially prevalent in various sectors of informal economy. In European countries, a large number of children work in seasonal, remunerated jobs, street trading and domestic work, for instance. The transition of some Eastern European countries to a market economy has also brought a resurgence of child labour in Central and Eastern Europe. Despite that, in some cases, children also in part work voluntarily for pocket money. 
ÍNDICE

Mots-clés: Europe, travail de mineurs, exploitation, marché du travail, jeunes

Palabras claves: Europa, trabajo infantil, explotación, mercado del trabajo, jóvenes

Keywords: Europe, child labour, exploitation, labour market, young people

Palavras-chave: Europa, trabalho de menores, exploração, mercado de trabalho, jovens

\section{AUTORES}

\section{GIANNI PAONE}

Sistema Servizi Nazionale CGIL Via IV Fontane, 108/00184 Roma Itália

g.paone@inca.it 